\title{
Policy and laws on ethnic minorities for sustainable development in Vietnam
}

\author{
Minh Phu Nguyen $^{1 *}$ \\ ${ }^{1}$ Vietnam Academy for Ethnic Minorities, Tay Mo, Tu Liem, Hanoi, 10000, Vietnam
}

\begin{abstract}
The formulation and implementation of policies and laws to serve the purpose of sustainable socio-economic development for ethnic minorities is a task and goal of not only the Party and the State but also the whole political system and people. In fact, to implement and concretize this point of view and objective, in the previous years, the Party and the State of Vietnam have always stayed focused on issuing policies and laws to solve ethnic issues in an effective manner, achieving praiseworthy results in all socio-economic, cultural, national defense and security aspects. However, in the realterm management and development of ethnic affairs in the new context, the resolution of ethnic issues in some places still expose certain shortcomings and downsides. As a result, continuously improving policies and laws on ethnic minorities to meet the demand for sustainable development in Vietnam at present is an important issue in the socio-economic development for ethnic minorities in Vietnam.
\end{abstract}

\section{Introduction}

Vietnam is a unified country with 54 ethnic groups co-inhabiting and residing in an interlocking manner in many areas across the country. Of all the local peoples, the Kinh people take the major proportion of the population. Vietnamese people have a tradition of solidarity. They have been standing side by side in the national construction and defense. In the course of leading the revolution, the Party has always attached great importance to ethnic issues. Many policies have been developed for ethnic minorities with a consistent principle of "equality, solidarity and support for mutual development". According to figures from the General Statistics Office (GSO) on April 1st, 2019, the Kinh people makes up $85.3 \%$ of the population while the remaining 53 ethnic minorities account for $14.7 \%$. Ethnic minorities mainly reside in mountainous regions with a vast area of three-fourths of the whole country. They even live in border areas with particularly important strategic positions with regard to politics, economy, national defense and security. The ethnic minorities in Vietnam have uneven populations and intertwine with one another without any separate territories, which creates favorable conditions for them to enhance their mutual understanding, solidarity and support for co-development. Policies introduced by the Party as well as laws enacted by the State have always been supported, welcomed and implemented by the people of all ethnic groups, creating a great motivation for and making important contributions to the victory of the national and democratic revolution and great

* Corresponding author: nguyenminhphugass@gmail.com 
achievements in the socialist revolution. Currently, to realize the requirement of promptly developing Vietnam into an industrialized and modernized country, it is a must to trigger comprehensive renovations from the perspectives of awareness and theory. The first task that needs to be implemented is to build a system of uniform policies and laws as well as achieve a consensus among the people in general and ethnic minorities in particular. This has important implications in formulating and promoting the great national unity bloc, successfully shaping the objectives of rich people, strong country, and equitable, democratic and civilized society.

\section{Materials and research methods}

The author has used the analytical method to analyze current policies and laws on ethnic minorities in Vietnam at present; using methods of analysis, integrated and statistical methods to make assessments of legal provisions and application of laws on the content of state management on ethnic minorities to meet the demand for sustainable development. Based on the analysis of laws and researching articles, reports and data related to ethnic minorities and sustainable development in Vietnam, the author makes recommendations that contribute to improving the efficiency of the state management of sustainable development in Vietnam at present.

\section{Development of policies and laws on ethnic minorities}

During the "Đổi Mới or renovation process", to improve the efficiency of addressing ethnic affairs, the Party issued many resolutions and directives such as Resolution No. 22-NQ/TW dated November 27th, 1989 by the Politburo on a number of major policies on socioeconomic development in mountainous areas; Resolution No. 24/NQ/TW dated 12th March, 2003 by the 9th Party's Central Committee on ethnic affairs; Directive No. 49CT/TW dated 20th October, 2015 by the Secretariat of the Party's Central Committee on the strengthening and renovating the Party's mass mobilization in ethnic minority areas and others. The Party's basic views, guidelines and policies on ethnicity and ethnic affairs are institutionalized in a great number of codes, laws, ordinances, decrees, resolutions, decisions, directives, circulars and others promulgated by competent authorities. In the period 2010-2015, apart from legal documents, the Government issued approx. 154 policies on ethnic issues, presented in 177 documents, 37 Government Decrees and Resolutions, and 140 Decisions of the Prime Minister. The system of policies and laws on ethnic issues, especially the ones regarding poverty reduction and social security is comprehensive in every aspect and covers all ethnic minority and mountainous areas. Many documents contain specific provisions on schemes and policies that are regularly amended and supplemented to suit the country's socio-economic development as well as the implementation of ethnic policies for specific regions or subjects. Numerous policies on ethnic minorities have been deeply embedded with renovative ideas and thinking such as attaching importance to openness and transparency, strengthening the coordination among ministries, sectors and localities, and emphasizing the people's role in policy realization. After coming into force, many of such policies have brought about good results and gained support from the majority of the people. According to the survey results, among respondents who are from ethnic minorities, $92.6 \%$ believe that the State's ethnic policies are good and quite good, only $2.8 \%$ think that the policies are not so good and $4.6 \%$ share that it is hard to evaluate. From these points, it can be concluded that policies and laws 
developed by the Party and the State of Vietnam are increasingly comprehensive, uniform, transparent, democratic and fair, thereby helping to improve the efficiency of ethnic issue resolution.

The Party and the State of Vietnam consider ethnic affairs as the fundamental, long-term and urgent strategic issue as well as task of the entire Party, people, army, and political system. The Party has issued many important documents related to ethnic issues and affairs. Resolution No. 24-NQ/TW dated March 12th, 2003 by the 9th Party's Central Committee has defined basic standpoints on, set out major and urgent goals and tasks for, and proposed some key solutions to ethnic affairs. On October 30th, 2019, the Politburo issued Conclusion No. 65-KL/TW on "Continuing to implement Resolution No. 24-NQ/TW by the 9th Party's Central Committee on ethnic affairs in the new context".

Regarding the institutionalization of the Party's policies, as of July 2019, the National Assembly has issued 108 laws and more than 30 resolutions on ethnic minorities and mountainous and especially difficult areas, covering all fields (civil affairs and politics; national defense, security, social order and safety guarantee; economic affairs, employment, culture and information; education, training, human resource development, people's intellect improvement; people's health care, environmental protection and political system development). The system of ethnic policies developed by the Government, ministries and sectors comprises 118 documents, including 54 ethnic projects and policies directly facilitating the socio-economic development in ethnic minority and mountainous areas.

\section{Implementation of policies and laws on ethnic minorities}

The Party's policy system and the State's laws on ethnic affairs applied for ethnic minorities in remote and extremely difficult areas have brought about positive impacts on all aspects of the social and economic life. To implement the Prime Minister's Decision No. 02/QDTTg dated 5th January, 2015, approving the Project on survey to collect of information about the socio-economic situation of 53 ethnic minorities on October 1st, 2019, the Committee on Ethnic Minority Affairs (CEMA) has collaborated with the General Statistics Office (GSO) to conduct a survey and collect such information for the second time. The survey to collect information about the socio-economic situation of 53 ethnic minorities provided comprehensive data on their populations, demographic characteristics, housing conditions, daily activities and spiritual and cultural life. Results of implementing policies and laws of the Party and the State are demonstrated in the following aspects:

\subsection{Socio-economic situation ethnic minority areas}

There are 5,468 ethnic minority and mountainous communes nationwide, accounting for $49.0 \%$ of the total number of communes throughout the country. The ethnic minority communes are mainly distributed in rural areas (87.3\%), under the management of 503/713 districts, towns and provincial cities in 54/63 provinces and centrally-run cities. By 2019 , $98.6 \%$ of villages in ethnic minority communes had get access to electricity. Specifically, the percentage of villages connected to the national grid had accounted for $97.2 \%$, increasing by $4.2 \%$ in comparison to 2015 .

The average distance from the center of an ethnic minority commune to the district center is $16.7 \mathrm{~km}$. The majority of roads from commune centers in ethnic minority areas to district centers had been hardened with the rate of kilometers hardened (with asphalt or concrete) reaching $95.2 \%$. Nearly $90 \%$ of ethnic minority villages have hardened roads to commune centers, which is nearly $17 \%$ higher in comparison to 2015 . 
The number of ethnic minority communes having health stations accounted for $99.5 \%$, equivalent to the 2015 survey results. Commune health stations in ethnic minority areas built in a permanent or semi-permanent manner reached $99.6 \%$, increasing by $0.8 \%$ in comparison to the figure in 2015. The rate of communes with health stations meeting the national standards of commune health facilities in the period to 2020 stood at $83.5 \%$, increasing by nearly twice in comparison to 2015 (45.8\%). 33.4 thousand medical leaders and workers were working at commune health stations in ethnic minority areas. In which, medical workers with qualifications of physicians or nurses occupied more than $50 \%$. $83.5 \%$ of villages in the ethnic minority communes have village health workers.

Nationwide, there were nearly 21.6 thousand schools and school branches in ethnic minority areas, increasing by more than 3.8 thousand schools and decreasing by 2.3 thousand school branches respectively in comparison to 2015. The proportion of permanent schools reached $91.3 \%$, increasing by $14.2 \%$ in comparison to 2015 , while the percentage of permanent school branches was only $54.4 \%$. The total number of teachers working at ethnic minority schools and school branches was nearly 525 thousand, of which 134.9 thousand teachers are ethnic people $(25.7 \%)$ and 99.6 thousand teachers are women from ethnic minorities (19.0\%).

The percentage of poor and near-poor households in ethnic minority areas was $35.5 \%$, decreasing by $1.2 \%$ in comparison to 2015 and increasing by 3.5 times compared to the national average (10.2\%). According to the survey results, there were 7,712 lonely and helpless old people in 5,468 communes of ethnic minority areas. In 2018, across the county, 1.2 million ethnic minority households residing in ethnic minority areas were eligible to receive cash or material support, which makes up $36.9 \%$ of the total number of ethnic minority households residing in ethnic minority communes.

\section{2. Population and demographic characteristics of ethnic minorities}

By April 1st, 2019, the population of 53 ethnic minorities had been 14.1 million, constituting $14.7 \%$ of the country's total population. After 10 years, from 2009 to 2019 , the population size of 53 ethnic minorities had increased by nearly 1.9 million people. The average annual population growth rate in the period $2009-2019$ was $1.42 \%$, higher than that of the Kinh people $(1.09 \%)$ and the whole country $(1.14 \%)$. Of which, men $(50.1 \%)$ made up a higher proportion than women (49.9\%). The gender ratio of 53 ethnic minorities was 100.4 males/100 females, higher than that of the whole country ( 99.1 males/100 females) and the Kinh people (98.8 males/100 females).

There number of ethnic minority households was 3,680,943, accounting for $13.7 \%$ of the total households nationwide. The majority of ethnic minority households (nearly 3,1 million) lived in rural areas, taking up $83.3 \%$. The average age of people from ethnic minorities getting married for the first time was 22.7 years old, which was lower than the average of the entire population ( 25.2 years old) and increased by 1.7 years in comparison to 2015 ( 21 years old). The child marriage rate of ethnic minorities in 2018 was $21.9 \%$ which decreased by $4.7 \%$ in comparison to 2014 or went down by more than $1 \%$ /year on average in other words. The proportion of people from ethnic minorities engaging in cousin marriage in 2018 was $5.6 \%$, dropping by $0.9 \%$ in comparison to 2014 (6.5\%o).

The total fertility rate (TFR) of ethnic minorities was 2.35 childs/woman, which decreased by $0.03 \mathrm{child} /$ woman in comparison to 2015 . However, it has remained quite high in comparison to the national average of 2.09 childs/woman and was higher than the replacement fertility of 2.1 children/woman. The sex ratio at birth was 110.2 boys/100 girls, 
lower than the national average (111.5 boys/100 girls); nevertheless, it was still higher than the biological balance (104-106 boys/100 girls).

The overall crude death rate (CDR) of 53 ethnic minorities was $7.65 \%$, higher than the national average in 2019 (6.3\%). Their average life expectancy was 70.7 years old, lower than the national average ( 73.6 years old); of which, the male and female life expectancies were respectively 68.0 years old and 73.7 years old. Specifically, the Hoa people had the highest average life expectancy ( 74.4 years old) while the La Hu people showed the lowest (59.4 years).

The rate of primary school attendance of people from ethnic minorities was $100.5 \%$, secondary school attendance $85.8 \%$ and high school attendance $50.7 \%$. In comparison to 2015, the access to basic education of people from ethnic minorities had been significantly improved, especially at the high school level with the overall attendance rate going up by $8.9 \%$.

The labor force participation rate of people from ethnic minorities aged 15 or older was $83.3 \%$. Such rate of men from ethnic minorities was $7.8 \%$ higher than that of their female counterparts. The labor force participation rate of people in rural areas was $12.9 \%$ higher than this rate of people in urban areas. The proportion of workers with professional and technical training at the elementary level or higher was $10.3 \%, 12.8 \%$ lower than the national average $(23.1 \%)$. This is a weak point of the labor force from ethnic minorities in getting access to the labor market and improving the labor productivity to create income.

Among the total number of employed people classified by modes of labor, the "unskilled labor" group still attracted a great stock of manpower (68.6\%) and mainly concentrated in the Agriculture, Forestry and Fishing sector $(92.2 \%$ of unskilled labor worked in this sector). However, in comparison to 2015, the proportion of unskilled labor had fell by $6.8 \%$. The number of workers in "self-employed" and "household labor" groups accounted for about $3 / 4$ of the total employed workers from ethnic minorities; of which, the "unpaid household labor" group made up $38.8 \%$. People from ethnic minorities acting as the "facility owners" occupied a very small proportion $(0.5 \%)$. Reviewing the job statuses of ethnic minorities with less than 10,000 people, it is indicated that the majority of employed workers belonged to unpaid "household labor" and "self-employed" groups - the groups of vulnerable and unstable jobs, mostly with no social insurance.

\subsection{Housing and living conditions and spiritual-cultural life of ethnic minority households}

According to the GSO's survey results, almost all ethnic minority households lived in houses (99.8\%). Among them, 95\% owned private houses and 5\% rented houses (from the state, individuals or collectives). The majority of ethnic minority households resided in permanent or semi-permanent houses, accounting for $79.2 \%$, which was $13.9 \%$ lower than the national average (93.1\%). 20.8\% of ethnic minority households still lived in makeshift or simple houses nationwide. The average housing area per capita of ethnic minority households $(16.9 \mathrm{~m} 2 /$ person) was $6.3 \mathrm{~m} 2 /$ person lower than the national average (23.2m $2 /$ person). Households living in traditional houses of their ethnic groups comprised $26.2 \%$, decreasing by $3.1 \%$ in comparison to $2015(29.3 \%) .96 .7 \%$ of ethnic minority households used power from the national grid for lighting, increasing by $2.8 \%$ in comparison to 2015. Most of ethnic minority households in urban areas had access to power from the national grid for lighting $(99.7 \%$ ), while $3.7 \%$ of ethnic minority households in rural areas did not get this access. The percentage of ethnic minority households using 
hygienic toilets (flush or semi-flush toilets) was $59.6 \%$, increasing by $31.7 \%$ in comparison to 2015 .

Television has become a common type of equipment used in the daily life with a rate of $81.5 \%$. The percentage of ethnic minority households using landline phones, mobile phones and tablets was $92.5 \%$, increasing by $17.1 \%$ in comparison to 2015 . The use rate of (desktop or portable) computers was $10.3 \%$, rising by $2.6 \%$ in comparison to 2015 . The percentage of households with Internet access improved significantly and accounted for $61.3 \%$ of the total ethnic minority households, increasing by $54.8 \%$ in comparison to 2015 . The prevalence of household appliances had increased sharply in comparison to 2015 . For example, the use rate of refrigerators had gone up by $22.3 \%(32.2 \%$ in 2015 and $54.5 \%$ in $2019)$ and air conditioners by $3.7 \%$ (2.9\% in 2015 and $6.6 \%$ in 2019). However, the number of households raising cattle and poultry beneath or near their houses nationwide remained at $24.4 \%$.

The proportion of ethnic minority households borrowing preferential loans from the Social Policy Bank in 2019 was $19.7 \%$. The social policy credit has offered ethnic minority households resources to develop their economic affairs, raise the level of production and business management, thereby improving the quality of life and creating incentives for sustainable poverty reduction.

The above results showed that the implementation of policies and laws on ethnic affairs of the Party and the State had yielded great achievements in all aspects of the social life. The right to equality among ethnic groups was fully realized in all fields. The economy of ethnic minority and mountainous areas achieved significant development with high annual economic growth rate (at $8 \% /$ year on average). The multi-actor economy has been initially formed, developed and shifted toward producing commodities and forming various areas specializing in crop cultivation. Infrastructure and socio-economic affairs has been developed in a sustainable manner. The poverty reduction has witnessed impressive success together with improved cultural and spiritual life and advanced people's intellect. Traditional culture of ethnic minorities was respected, preserved and promoted. Primary education has been fully universalized. The medical examination and treatment for poor people in remote areas and especially difficult areas has been increasingly paid more attention to with many priority policies. The political system in ethnic minority and mountainous areas has been strengthened and reinforced, especially at the grassroots level. The development of Party cells in ethnic minority areas has been attached importance to. Basically, the political and social order in the ethnic minority and mountainous areas has been stabilized. The national defense and security there have been also upheld. International cooperation in ethnic affairs has been developed through the coordination with international partners in carrying out research on and exchanging experience of ethnic affairs as well as encouraging and supporting investments to develop ethnic minority areas. The external communication and exchange had made considerable contributions to the mutual understanding between ethnic groups in Vietnam and other ethnic groups in the region and world.

\subsection{Shortcomings and downsides}

Despite the above mention success and achievements, the resolution of ethnic issues has, recently, still exposed some shortcomings and downsides that need to be addressed. The development and implementation of policies and laws on ethnic minorities remain short of policy-making regulations. Furthermore, the clear and specific allocation on tasks, authorities and responsibilities of each level in promulgating policies and schemes is still 
missing. Many issues of ethnic minorities have been identified by the Party in documents and resolutions but not been fully and promptly reflected in government laws, ordinances and resolutions yet. On the other hand, many contents in ethnic policies are overlapped, fail to match the reality or fall short of resources for implementation. Furthermore, the inspection, review and summary of ethnic policies have not been carried out on a regular basis, limiting the effectiveness of the system of policies and laws on ethnic minorities.

In recent years, although the economy of ethnic minority areas has developed quite fast, its contributions to the national economy remain low and incommensurate to its potential. The economic structure transition has taken place slowly. Highly-spontaneous agricultural production has still accounted for a large share, as well as small production has failed to unleashed the potential and strengths of each region. Meanwhile, processing industry has not developed; trade and services have not met the demand on production and the living requirements of ethnic minorities. Despite huge achievements of the poverty reduction in comparison to the previous period, the rate of poor households according to the multidimensional poverty standard has remained high. As a result, many ethnic minorities and areas have lower levels of socio-economic development than the national average.

The grassroots political system in some ethnic minority areas has been still weak. The social management, especially in remote and border areas, has not been close to local people and failed to satisfy their expectations. The officials who are from ethnic minorities have improved in quantity, but their quality is not high due to lack of specialized training in state management, laws and economics.

Despite notable progress in many aspects of socio-cultural life of ethnic minorities, the people's spiritual and cultural enjoyment has not indicated clear advances. Information communication and reception have still run into numerous difficulties. The erosion of traditional cultural identities of many ethnic groups, especially ethnic minorities, is evermore visible. The health status of people from ethnic minorities has been improved yet in still failed to keep up with the national average. In addition, the child mortality, malnutrition, fertility and maternal mortality rates have not shown any declining signs. Healthcare services have not yet been able to satisfactorily meet the needs for medical examination and treatment of people from ethnic minorities.

Many hard-to-control factors have been regularly found in maintaining the social order and security. Moreover, illegal logging and deforestation for kaingins, and forest fires in many places have left direct impacts on the forest coverage and climate change. Moreover, illegal drug trafficking, opium replanting, drug addiction, HIV infection, cousin marriage, accidents, free migration, deception, trafficking in women and children, illegal labor across borders and others have continues to take place in a complicated manner.

\section{Some solutions to improve the development and implementation of policies and laws on ethnic minorities}

To overcome the above inadequacies and shortcomings, it is a must to have the drastic involvement of the entire political system across all levels and industries. At the same time, the whole Party, army and people must synchronously implement many solutions with priorities over the following contents:

Firstly, it is necessary to raise the awareness of state officials, Party's members and society as a whole in formulating and implementing policies and laws on ethnic minorities and solving ethnic issues. It is required to be consistent in the awareness and ideology from the central to local levels on ethnic issues as well as on the role and responsibilities of agencies and the entire political system in ethnic affairs with state officials and Party's members as 
the frontline force. Moreover, it is a must to effectively disseminate and communicate policies and laws of the Party and the State, especially the ones on the socio-economic development to people from ethnic minorities in hamlets and villages. These are the most effective solutions in the fight against all plots of destroying the great solidarity among ethnic groups in Vietnam.

Secondly, policies and laws on ethnic issues need to be continuously improved and ensured in terms of their comprehensiveness, effectiveness, fairness and sustainable development for people from ethnic minorities. Moreover, the system of ethnic policies that have been implementing should be reviewed and revised on a regular basis. Policies and laws, which are no longer fit the reality and adversely affect the comprehensive and sustainable development in all economic, political and social aspects of ethnic minority areas should be removed. In addition, the formulation of policies needs to be based on geographical areas and development levels associated with building new-style rural areas and promoting commodity production. In addition, it is needed to identify clearly the priorities and focal points in policy development and formulate specific policies which match natural and cultural conditions as well as are in close linkage to poverty reduction and sustainable development policies. Furthermore, it is crucial to enhance the quality of human resources, preserve and promote the cultural identity of each ethnic group and each ethnic minority area.

Thirdly, executive committees of the Party from the central to local levels need to renovate and strengthen their leadership when addressing ethnic affairs. They should focus on leading and directing the concretization, institutionalization and implementation of the Party's policies and the State's laws in all areas and, as while paying attention to the quality enhancement for state officials working on ethnic affairs. Additionally, renovating the leadership in ethnic issues to suit the new situation of socio-economic development and international integration of Vietnam is highly required.

Fourthly, it is a must to prioritize investments in the socio-economic development and improvement in the material and spiritual life of people from ethnic minorities. In economic development, the planning needs to be reviewed, supplemented and finalized to suit each region, especially the key areas. Objectives and requirements in developing the strengths of each region must be also clearly identified. At the same time, formulating sound policies and creating favorable environment to attract capital investment to develop competitive and advantageous infrastructure, programs and projects are other factors to be focused. People from ethnic minorities should be also encouraged to start businesses and be self-reliant in becoming well-off and developing economic affairs such as operation of farms, cooperatives, enterprises and others. Furthermore, it is necessary to renovate the methods of financial support for production toward focusing on an unsecured management and guarantee focal agency, avoiding small-scale support. Gaining on the ground, the quote "Give a man a fish and he'll eat for a day; Teach a man to fish and he'll eat for a lifetime" should always be born in mind.

In addressing socio-cultural issues, leadership and management methods need to be renovated; development and conservation must go together to promote the strengths and cultural traditions of ethnic groups. In education, it is important to improve the teaching and learning qualities while avoiding re-illiteracy in order to universalize the secondary education for people from ethnic minorities. In the health sector, facilities and equipment also require adequate investments. The quality of medical workers should be continuously improved. Appropriate health care and community health policies need to be developed, eliminating cousin marriage and child marriage.

Fifthly, the role of the Vietnam Fatherland Front and mass organizations in addressing issues related to ethnic groups and national solidarity should be promoted. The Vietnam 
Fatherland Front and mass organizations should participate actively in propagating and mobilizing the whole people to implement ethnic policies and coordinate with the executive committees and authorities in communicating the Party's policies and the State's laws in building and developing all aspects of the socio-economic and political life. Integrating with and getting access to advanced and information technologies also need to be focused. Moreover, these forces need to work together to guide people from ethnic minorities to eliminate backward customs, social evils and so on. Other factors that the Vietnam Fatherland Front and mass organizations are required to pay attention to include renovating operation contents and modalities, formulating plans, making counter-arguments on policies and laws, and supervising the implementation of these policies to keep enhancing the effectiveness and efficiency in addressing issues with regard to policies and laws on ethnic minorities.

Sixthly, the fight against subjects taking advantages of ethnic and religious issues to incite subversion of the Party's policies and the State's laws needs to be consolidated. The international integration and cooperation in issues related to ethnic minorities should be strengthened. It is also essential to build a transparent and strong political system to increase the effectiveness and efficiency in the implementation of ethnic policies and laws. The human rights, citizens' rights and equality among ethnic groups also need to be fully honored, thereby reinforcing the whole people's trust in the Party and the State.

Seventhly, it is imperative to effectively implement Resolution No. 88/2019/QH14 dated 18th November, 2019 by the 8th Plenum of the 14th National Assembly, approving the overall plan on socio-economic development in ethnic minority and mountainous areas in the period 2021-2030. The general goal of this plan is to "Exploit the potential and advantages of localities in the region, renovate and promote economic development, thereby ensuring social security, reducing poverty in a rapid and sustainable manner, narrowing the gap between living standards and incomes in comparison to the national average and gradually reducing the number of especially difficult communes and villages. Furthermore, planning and arranging to stabilize the population, building a synchronous and inter-regional socio-economic infrastructure system, connecting with developed regions, comprehensively developing education, training, health care and culture are also prerequisite conditions to improve living standards of the whole people, increase the quantity and quality of the contingent of civil servants, state officials and employees from ethnic minorities, preserve and promote the good cultural identity of ethnic minorities in parallel with removing backward customs and practices, perform gender equality and address urgent issues for women and children. In addition, building a strong political system; maintaining political security, social order and safety; ensuring national border security; consolidating and strengthening the great unity bloc of ethnic groups; strengthening the trusts of ethnic minorities in the Party and the State should be prioritized as well". At the same time, it is required to "review legal documents related to ethnic minority and mountainous areas and ethnic policies together with proposing, amending, supplementing, replacing and abolishing related documents which are no longer suitable to ensure the uniformity and synchronization of the legal system, aiming at implementing the Project's contents effectively".

\section{Conclusion}

To implement Resolution of the central Government, Conclusion of the Politburo and Resolution of the National Assembly on ethnic affairs in the new context, state agencies from central to local levels should understand comprehensively the spirit of the above- 
mentioned documents, direct and implement them in a close and effective manner. Agencies at all levels also need to develop programs, plans and schedules with specific and detailed contents to mobilize and promote all social resources, especially the contributions of experts and scientists involving in the development, dissemination, education and implementation of policies and laws to ensure the security, national defense and sustainable economic-politic-social development for ethnic minority and mountainous areas in Vietnam.

From the practical situation of ethnic issues mentioned above, it could be concluded that the Party and the State as well as the entire political system always pay attention to and prioritize the formulation and implementation of ethnic policies and laws. This is aimed at facilitating the socio-economic and political development in ethnic minority areas in a sustainable way, forming the great unity bloc in people as a whole, promoting the strength of all ethnic groups co-inhabiting in the Vietnamese territory and implementing successfully the goal of building the socialist rule-of-law State of rich people, strong country, and equitable, democratic and civilized society.

\section{References}

1. The Communist Party of Vietnam: Document of the Seventh Plenum of the 9th Party's Central Committee (National Political Publishing House, Hanoi, 2003)

2. The Committee for Ethnic Minority Affairs. Report in the "Workshop on proposing ethnic policies in the period 2016 - 2020 (Hanoi, September 2015)

3. Phan Van Hung "The National Assembly's decisive role in addressing issues in the implementation of ethnic policies at present", July 2019.

4. The national standards on commune health facilities in the period to 2020, issued together with Decision No. 4667/QD-BYT dated 7th November, 2014.

5. The National Assembly. Resolution on "Approving the master project on socio-economic development of ethnic minority and mountainous areas in the period 2021-2030. (Hanoi, November, 2019)

6. Vietnam National Project on "Agricultural, farmers and rural issues" Institute of Policy and Strategy for Rural Agriculture Development Agriculture Newspaper, 4 (153) (2018)

7. Chau Van Ly, VN-Economy, 6 (230) (2019)

8. Prime Minister of Vietnam, Speech to promote enterprises investing in agriculture, Hanoi (2018).

9. Nguyen Huyen My, Journal of Industry and Trade, 12 (2019).

10. Abbott, P., Tarp, F. \& Wu, C. Structural Transformation, Biased Technological Change and Employment in Vietnam. Eur J Dev Res 29, 54-72 (2017). DOI: 10.1057/ejdr.2015.64

11. Peters, J. Transforming the "model" approach to upland rural development in Vietnam. Agriculture and Human Values 18, 403-412 (2001). DÒI: $10.1023 / \mathrm{A}: 1015225208482$

12. Lan, N.T.P. Social and ecological challenges of market-oriented shrimp farming in Vietnam. Springer Plus 2, 675 (2013). DOI: 10.1186/2193-1801-2-675 